\title{
Desempenho agronômico de híbridos de milho em três épocas de semeadura no Cerrado goiano
}

\author{
Wilian Henrique Diniz Buso ${ }^{1}$, Luciana Borges e Silva ${ }^{1}$, Sandra Máscimo da Costa e Silva ${ }^{2}$, \\ Laidson Alves Leão Junior ${ }^{1}$ \\ ${ }^{1}$ Instituto Federal Goiano, Campus Ceres, Ceres, Goiás, Brasil. E-mail: wilian.buso@ifgoiano.edu.br, luciana.silva@ifgoiano.edu.br, \\ lalj@outlook.com.br \\ ${ }^{2}$ Universidade Estadual de Goiás, Campus Anápolis, Anápolis, Goiás, Brasil. E-mail: sandramascimo@ hotmail.com
}

Recebido: 06/07/2017; Aceito: 21/10/2017.

\section{RESUMO}

Avaliou-se o desempenho agronômico de híbridos de milho em três épocas de semeadura no município de CeresGO. O experimento foi desenvolvido na Fazenda Experimental do IF Goiano Campus Ceres. O delineamento experimental foi o de blocos completos casualizados em esquema fatorial 10x3, dez híbridos de milho (Truck, Fórmula, P30F53, P3646H, P30F35H, AGN 30A91H, AGN 30A37H, AG 8088VTPRO, DKB 390 e DKB bi 9438) semeados em três épocas (30/11/2011, 01/02/2012 e 20/02/2012), com três repetições. Os híbridos que apresentaram maior número de fileira de grãos foram Truck, Formula, P30F35H, AG8088PRO. Para altura de planta e da primeira espiga e o diâmetro do colmo houve diferença estatística nas épocas de semeadura. O híbrido DKB Bi 9438 diferiu estatisticamente dos demais para massa de 1000 grãos. Na semeadura de 30/11/2011, os diâmetros de espiga maior foram para os híbridos Truck, P3646H, P30F35H e DKB 390. O híbrido DKB Bi 9438 diferiu estatisticamente, para comprimento de espiga, dos demais na semeadura de 30/11/2012. A semeadura de 30/11/2011 diferiu das demais épocas para produtividade. Os híbridos favoráveis para produção em época de altos índices pluviométricos (30/11/2011) foram o DKB Bi 9438 e o P3646H.

Palavras-chave: Cultivares, caracteres agronômicos, Zea mays L.

\section{Agronomic performance of maize hybrids at three sowing times in the brazilian cerrado}

\begin{abstract}
The performance of maize hybrids in three sowing seasons in the municipality of Ceres-GO was evaluated. The experiment was carried out at the Goiano Campus Ceres Experimental Farm. The experimental design was a randomized complete block in a 10x3 factorial scheme, ten corn hybrids (Truck, Formula, P30F53, P3646H, P30F35H, AGN 30A91H, AG 8088VTPRO, DKB 390 and DKB Bi 9438). 11/30/2011, 02/01/2012 and 02/20/2012), with three replications. The hybrids that presented the highest number of grain rows were Truck, Formula, P30F35H, AG8088PRO. For height of plant and first ear and stem diameter there was statistical difference in sowing times. The DKB Bi 9438 hybrid differed statistically from the others for 1000 grain mass. In the sowing of 11/30/2011, the larger spike diameters were for the Hybrids Truck, P3646H, P30F35H and DKB 390. The hybrid DKB Bi 9438 differed statistically, for ear length, from the others in the sowing of 11/30/2011. The sowing of 11/30/2011 differed from the other sowing times for yield. The favorable hybrids for production during high rainfall (11/30/2011) were the DKB Bi 9438 and the P3646H.
\end{abstract}

Key words: Hybrids, agronomical traits, Zea mays L. 


\section{Introdução}

O milho (Zea mays L.) é uma planta que pertence à família Poaceae, cuja espécie apresenta maior potencial produtivo (PORTO et al., 2011). Pode ser cultivado praticamente em todas as regiões agrícolas do mundo, tendo sua importância econômica caracterizada pelas diversas formas de sua utilização; desde a alimentação animal até a indústria de alta tecnologia, como na produção de cereal matinal, amido de milho e outros (FORNASIERI FILHO, 2007. No Brasil na safra 2015/2016 foram semeados 15.922,5 milhões de hectares com produtividade média de $4.178 \mathrm{~kg} \mathrm{ha}^{-1}$, e para a safra 2016/2017 foram semeados 16.772 milhões de hectares com expectativa de produtividade de 5.305 $\mathrm{kg} \mathrm{ha}{ }^{-1}$, totalizando $88.969,4$ milhões de toneladas (CONAB, 2017).

Em uma economia globalizada e de alta competitividade, a busca por maior eficiência na produção tem sido constante em toda cadeia produtiva. Isso é especialmente importante para o agricultor que tem por objetivo obter a máxima produtividade com o menor custo de produção, para que sua atividade se torne competitiva e sustentável (CRUZ et al., 2009).

A época de semeadura promove alteração no ciclo da cultura e modifica aspectos fisiológicos e morfológicos que podem afetar os componentes de produção. Em pesquisas realizadas no Brasil relacionadas com o desempenho agronômico de híbridos, apenas alguns estudos reportaram a influência da época de semeadura nos componentes da produção de grãos, bem como a adaptação dos híbridos a uma condição de estresse hídrico (SOUZA et al., 2015).

De acordo com Buso e Arnhold (2016) trabalhando com vários híbridos de milho sob déficit hídrico observaram que o híbrido AGN 30A77H apresentou maior capacidade adaptativa de acordo com a variação da disponibilidade hídrica.

Diante do exposto, objetivou-se com o este trabalho avaliar o desempenho agronômico de dez híbridos de milho em três épocas de semeadura na região do Vale de São Patrício.

\section{Material e Métodos}

O experimento foi conduzido na Fazenda Experimental do Instituto Federal Goiano (IF Goiano), Campus Ceres, no município de Ceres, Goiás, localizada na latitude $15^{\circ} 21^{\prime} 02^{\prime \prime}, \mathrm{S}$, longitude $49^{\circ} 35^{\prime} 36^{\prime \prime}$ 'W e altitude de $564 \mathrm{~m}$, sob plantio direto. A área foi conservada em pousio antes da instalação do experimento. Os dados de distribuição pluviométrica e temperatura média mensal encontram-se na Figura 1.

O solo da área foi classificado como Latossolo Vermelho Distrófico, com as seguintes características, em termos de fertilidade, na camada de $0-20 \mathrm{~cm}: \mathrm{Ca}=$
2,4 $\left(\mathrm{cmol}_{\mathrm{c}} \mathrm{dm}^{-3}\right) ; \mathrm{Mg}=1,3\left(\mathrm{cmol}_{\mathrm{c}} \mathrm{dm}^{-3}\right) ; \mathrm{K}=0,26$ $\left(\mathrm{cmol}_{\mathrm{c}} \mathrm{dm}^{-3}\right) ; \mathrm{Al}=0,0\left(\mathrm{cmol}_{\mathrm{c}} \mathrm{dm}^{-3}\right) ; \mathrm{H}=3,5\left(\mathrm{cmol}_{\mathrm{c}} \mathrm{dm}^{-}\right.$ $\left.{ }^{3}\right) ; \mathrm{P}=5,6\left(\mathrm{mg} \mathrm{dm}^{-3}\right) ; \mathrm{K}=101,0\left(\mathrm{mg} \mathrm{dm}^{-3}\right) ; \mathrm{pH}=5,0$ $\left(\mathrm{CaCl}_{2}\right)$; saturação por bases $51,80 \%$ e M.O. $=1,5 \mathrm{~g} \mathrm{~kg}^{-}$ ${ }^{1}, \mathrm{CTC}=7,67$.

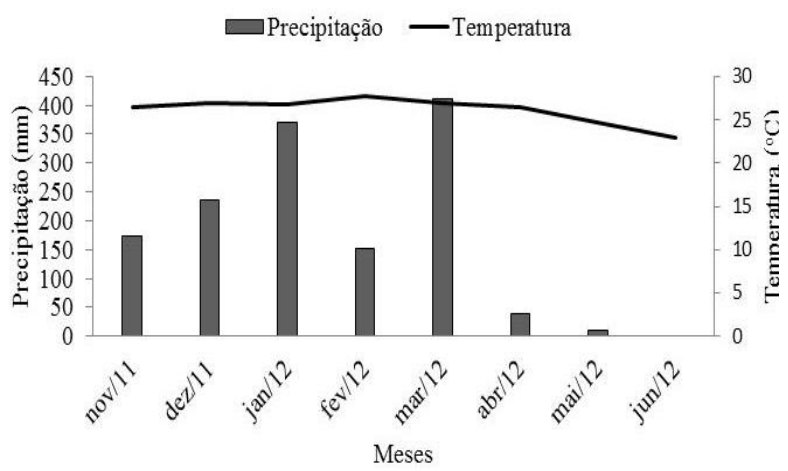

Figura 1. Precipitação mensal e temperatura média mensal durante o período experimental. Fonte: Estação meteorológica do IF Goiano Campus Ceres.

O delineamento experimental utilizado foi o de blocos completos casualizados em esquema fatorial 10x3, dez híbridos de milho (Truck, Fórmula, P30F53, P3646H, P30F35H, AGN 30A91H, AGN 30A37H, AG 8088VTPRO, DKB 390 e DKB Bi 9438) semeados em três épocas diferentes (30/11/2011, 01/02/2012 e 20/02/2012), com três repetições.

Foi realizada a dessecação das plantas daninhas sete dias antes da semeadura com $3 \mathrm{~L} \mathrm{ha}^{-1}$ de glifosato. A semeadura foi realizada nos dias 30/11/2011, 01/02/2012 e 20/02/2012, na mesma área um ao lado do outro. As sementes foram tratadas com tiametoxan + fipronil $(200 \mathrm{~mL}$ para $100 \mathrm{~kg}$ de sementes de produto comercial).

A adubação de semeadura foi de $20 \mathrm{~kg} \mathrm{ha}^{-1}$ de nitrogênio, $150 \mathrm{~kg} \mathrm{ha}^{-1}$ de fósforo e $80 \mathrm{~kg} \mathrm{ha}^{-1} \mathrm{de}$ potássio fornecidos pela formula 04-30-16. As adubações em cobertura ocorreram quando as plantas estavam em V5, aplicando-se $40 \mathrm{~kg} \mathrm{ha}^{-1}$ de $\mathrm{N}$ e $40 \mathrm{~kg}$ $\mathrm{ha}^{-1}$ de potássio (20-00-20), e em V8, foram distribuídos $90 \mathrm{~kg} \mathrm{ha}^{-1}$ de $\mathrm{N}$ (ureia). Aplicou-se o herbicida atrazina em pós- emergência na dosagem de $3 \mathrm{~L} \mathrm{ha}^{-1}$ quando a cultura estava em $\mathrm{V}_{4}$ visando o controle de plantas daninhas. Não foi realizada aplicação de inseticidas e fungicidas durante a condução do experimento, a tecnologia $\mathrm{Bt}$ foi eficiente no controle de lagartas e não ocorreu incidência de doenças.

Cada parcela foi constituída de quatro linhas de cinco metros espaçadas de $0,50 \mathrm{~m}$ entre linhas. As avaliações procederam nas duas linhas centrais das parcelas deixando $0,50 \mathrm{~m}$ de bordadura nas extremidades. A colheita foi realizada em 04/04/2012, $10 / 06 / 2012$ e 01/07/2012, respectivamente, para as três épocas de semeadura. 
As variáveis analisadas foram: altura da primeira espiga (APE), em metros; altura da planta (AP), em metros; diâmetro do colmo (DC), em milímetros, conforme metodologia de Demétrio et al. (2008), diâmetro da espiga (DE), em milímetros; comprimento (CE) da espiga, medida em milímetros com paquímetro digital; número de fileira de grãos (NFG); número de grãos por fileira (NG/F); massa de mil grãos (M1000) em gramas; produtividade (PROD) em quilograma por hectare. Após a colheita foi realizada a retirada da palha de todas as espigas e debulhadas manualmente, em seguida pesadas em balança digital. A umidade dos grãos de cada parcela foi corrigida para $13 \%$ e calculada a produtividade em $\mathrm{kg} \mathrm{ha}^{-1}$.

Os dados de todas as variáveis foram submetidos à análise de variância e as médias comparadas pelo teste de Scott-Knott com nível de significância de 5\%. As análises estatísticas foram realizadas com auxílio do software R (R Development Core Team, 2014) com o pacote easyanova (ARNHOLD, 2013).

\section{Resultados e Discussão}

Não ocorreu interação significativa $(\mathrm{P}>0,05)$ entre híbridos e épocas de semeadura para AP, APE, DC, NFG e MG. Para AP, APE e DC. Assim, estas variáveis foram analisadas individualmente. Ouve diferença estatística $(\mathrm{P}<0,05)$ entre todas as épocas de semeadura, demonstrando que a semeadura em 20/02/2012 reduziu o porte da planta e a altura da espiga, pois a cultura exposta a estresse hídrico resultou em redução no desenvolvimento, sendo estas variáveis afetadas pelo encurtamento dos entre nós (Tabela 1). O diâmetro do colmo reduziu $(\mathrm{P}<0,05)$ de 20,72 $\mathrm{mm}$ para 19,06 $\mathrm{mm}$ entre semeadura de 30/11/2011 e 20/02/2012. Entre os híbridos não ocorreu diferença $(\mathrm{P}>0,05)$ para esta variável; o mesmo foi verificado por Araújo et al. (2013) que não observaram diferença no diâmetro do colmo dos híbridos SHS 4080 e IAC 8333.

A redução do diâmetro do colmo é um parâmetro importante a ser trabalhado nos experimentos com milho pois colmos finos e com espigas pesadas e inserção de espigas muito alta, aumenta a probabilidade de queda ou inclinação da planta, o que dificulta a colheita (BALBINOT; FLECK, 2005). De acordo com Farinelli et al. (2003) os híbridos de milho apresentaram valores baixos de altura de plantas e inserção da primeira espiga em cultivos tardios devido às condições ambientais, redução de temperatura e disponibilidade de água.

$\mathrm{O}$ número de fileiras de grãos foi estatisticamente igual $(\mathrm{P}>0,05)$ entre as épocas de semeadura 30/11/2011 e 01/02/2012 cujos valores foram 16,10 e 16,15, respectivamente, sendo diferente $(\mathrm{P}<0,05)$ para a época 20/02/2012 que apresentou 15,58 fileiras de grãos (Tabela 1). A redução no número de fileiras de grãos nesta última época foi devida à menor disponibilidade hídrica ocorrida no período de florescimento; no mês de abril a precipitação total alcançou aproximadamente 50 mm (Figura 1).

Houve redução $(\mathrm{P}<0,05)$ na massa de mil grãos entre todas as épocas cujos valores foram de 344,5 g; 222,0 g e 198,4 g, respectivamente, para 30/11/2011, 01/02/2012 e 20/02/2012. A massa de mil grãos diminuiu devido à redução de temperatura e a disponibilidade hídrica ocorrida nas semeaduras tardias formando grãos mais leves.

Tabela 1. Valores médios relativos aos caracteres altura de planta (AP), altura da primeira espiga (APE), diâmetro do colmo (DC), número de fileiras de grãos (NFG) e massa de 1000 grãos (M1000), de híbridos de milho semeados em diferentes épocas na Fazenda Experimental do IF Goiano, Campus Ceres, Goiás.

\begin{tabular}{lccccc}
\hline Época de semeadura & AP $(\mathrm{m})$ & APE $(\mathrm{m})$ & DC $(\mathrm{mm})$ & NFG & M1000 (g) \\
\hline $30 / 11 / 2011$ & $2,20 \mathrm{a}$ & $1,05 \mathrm{a}$ & $20,72 \mathrm{a}$ & $16,10 \mathrm{a}$ & $344,5 \mathrm{a}$ \\
$01 / 02 / 2012$ & $1,83 \mathrm{~b}$ & $0,94 \mathrm{~b}$ & $20,03 \mathrm{~b}$ & $16,15 \mathrm{a}$ & $222,0 \mathrm{~b}$ \\
$20 / 02 / 2012$ & $1,59 \mathrm{c}$ & $0,81 \mathrm{c}$ & $19,06 \mathrm{c}$ & $15,58 \mathrm{~b}$ & $198,4 \mathrm{c}$ \\
\hline Híbridos & AP $(\mathrm{m})$ & APE $(\mathrm{m})$ & DC $(\mathrm{mm})$ & NFG & M1000 (g) \\
\hline Truck & $1,88 \mathrm{~b}$ & $0,97 \mathrm{a}$ & $20,12 \mathrm{a}$ & $17,11 \mathrm{a}$ & $238,7 \mathrm{c}$ \\
Formula & $1,89 \mathrm{~b}$ & $0,83 \mathrm{~b}$ & $19,85 \mathrm{a}$ & $16,94 \mathrm{a}$ & $211,3 \mathrm{c}$ \\
P30F53H & $1,89 \mathrm{~b}$ & $1,00 \mathrm{a}$ & $20,76 \mathrm{a}$ & $15,72 \mathrm{~b}$ & $254,5 \mathrm{~b}$ \\
P3646H & $1,81 \mathrm{~b}$ & $0,88 \mathrm{~b}$ & $20,27 \mathrm{a}$ & $15,61 \mathrm{~b}$ & $255,4 \mathrm{~b}$ \\
P30F35H & $2,06 \mathrm{a}$ & $0,99 \mathrm{a}$ & $20,91 \mathrm{a}$ & $16,27 \mathrm{a}$ & $246,9 \mathrm{~b}$ \\
AGN30A77H & $1,86 \mathrm{~b}$ & $0,94 \mathrm{a}$ & $19,87 \mathrm{a}$ & $15,78 \mathrm{~b}$ & $270,8 \mathrm{~b}$ \\
AGN30A37H & $1,75 \mathrm{~b}$ & $0,86 \mathrm{~b}$ & $19,03 \mathrm{a}$ & $15,22 \mathrm{~b}$ & $257,7 \mathrm{~b}$ \\
AG8088PRO & $1,81 \mathrm{~b}$ & $0,86 \mathrm{~b}$ & $19,49 \mathrm{a}$ & $17,05 \mathrm{a}$ & $228,09 \mathrm{c}$ \\
DKB 390 & $1,79 \mathrm{~b}$ & $0,95 \mathrm{a}$ & $19,20 \mathrm{a}$ & $15,61 \mathrm{~b}$ & $267,90 \mathrm{~b}$ \\
DKB Bi 9438 & $1,99 \mathrm{a}$ & $1,07 \mathrm{a}$ & $19,86 \mathrm{a}$ & $14,11 \mathrm{c}$ & $318,30 \mathrm{a}$ \\
\hline CV $(\%)$ & 6,28 & 11,26 & 6,27 & 6,2 & 9,72 \\
\hline
\end{tabular}

Médias seguidas da mesma letra nas colunas são estatisticamente iguais pelo teste de Scott-Knott a 5\% de probabilidade. 
Segundo Forsthofer et al. (2006), em semeadura tardia, o enchimento de grãos ocorre em períodos de déficit hídrico, temperaturas e radiação solar incidente menor que limita a atividade fotossintética e a translocação de fotoassimilados das frações vegetais para os grãos. De acordo Silva et al. (1999) o efeito da semeadura tardia reduz a massa de mil grãos. Um dos fatores que influenciam no menor peso específico do grão está relacionado com a redução na temperatura e na disponibilidade de água.

O híbrido DKB Bi 9438 foi estatisticamente superior $(\mathrm{P}<0,05)$ para a massa de mil grãos em relação aos demais, apresentando massa de 318,30 g. Por possuir grãos longos e com maior densidade é possível que este híbrido tenha alcançado também maior produtividade.

Mendes et al. (2011) trabalharam com quatro híbridos (P30P34, Formula, NK7G27 e P30R50) verificaram que o híbrido formula apresentou menor massa de 1000 grãos que os demais (Tabela 1). Este mesmo híbrido teve massa de 1000 grãos inferior $(\mathrm{P}<0,05)$ aos demais avaliados, fato que pode ter ocorrido devido à maior sensibilidade deste híbrido às condições ambientais em que a pesquisa foi desenvolvida.

Os híbridos com o número de fileira de grãos estatisticamente superior $(\mathrm{P}<0,05)$ foram: Truck, Formula, P30F35H, AG8088PRO, com valores entre 17,11 e 16,27 fieiras. O híbrido DKB Bi 9438 diferiu estatisticamente $(\mathrm{P}<0,05)$ dos demais híbridos para o número de fileiras de grãos com 14,11 fileiras, sendo o de menor desempenho para esta variável avaliada.

Segundo Caron et al. (2017), a cultura do milho, quando semeada em setembro, está sujeita a melhores condições meteorológicas, durante o crescimento e o desenvolvimento vegetativo, permitindo assim, que plantas acumulem mais carboidratos entre o pré e o póspendoamento, aumentando a massa dos grãos. Neste estudo, as restrições de ambiente fizeram com que houvesse um menor desenvolvimento, acarretando menor diâmetro de colmo para a época de março (DEMÉTRIO et al., 2008).

Ocorreu interação significativa $(\mathrm{P}<0,05)$ entre híbridos e épocas de semeadura para o diâmetro da espiga, conforme demonstrado na Tabela 2.

Para semeaduras feitas no dia 30/11/2011, os maiores diâmetros das espigas foram para os híbridos Truck, P3646H, P30F35H e DKB 390, cujos valores foram de 50,61; 51,25; 50,47 e 51,61 mm, respectivamente (Tabela 2). Na semeadura realizada em 01/02/2012 somente o híbrido AGN30A37H diferiu estatisticamente $(\mathrm{P}<0,05)$ dos demais apresentando menor valor $(39,97 \mathrm{~mm})$ para esta variável analisada. $\mathrm{Na}$ última época de semeadura não houve diferença estatística $(\mathrm{P}>0,05)$ entre os híbridos testados.
Os híbridos Truck e P30F35H também apresentaram maior número de fileira de grãos, conforme Tabela 1 . Estes dois fatores podem contribuir para aumento em produtividade.

Tabela 2. Desdobramento da interação entre híbridos e época de semeadura para diâmetro da espiga $(\mathrm{mm})$, na Fazenda Experimental do IF Goiano Campus Ceres, Goiás (2011/2012).

\begin{tabular}{lccc}
\hline \multirow{2}{*}{ Híbridos } & \multicolumn{3}{c}{ Épocas de semeadura } \\
\cline { 2 - 4 } & $30 / 11 / 2011$ & $01 / 02 / 2012$ & $20 / 02 / 2012$ \\
\hline Truck & $50,61 \mathrm{aA}$ & $49,90 \mathrm{bA}$ & $39,68 \mathrm{cA}$ \\
Formula & $48,37 \mathrm{aB}$ & $43,47 \mathrm{bA}$ & $41,09 \mathrm{cA}$ \\
P30F53H & $48,86 \mathrm{aB}$ & $42,86 \mathrm{bA}$ & $39,21 \mathrm{cA}$ \\
P3646H & $51,25 \mathrm{aA}$ & $43,98 \mathrm{bA}$ & $40,32 \mathrm{cA}$ \\
P30F35H & $50,47 \mathrm{aA}$ & $44,98 \mathrm{bA}$ & $42,90 \mathrm{cA}$ \\
AGN30A77H & $49,31 \mathrm{aB}$ & $43,62 \mathrm{bA}$ & $39,26 \mathrm{cA}$ \\
AGN30A37H & $47,51 \mathrm{aB}$ & $39,97 \mathrm{bB}$ & $39,84 \mathrm{bA}$ \\
AG8088PRO & $47,49 \mathrm{aB}$ & $42,48 \mathrm{bA}$ & $40,51 \mathrm{bA}$ \\
DKB 390 & $51,61 \mathrm{aA}$ & $44,09 \mathrm{bA}$ & $40,14 \mathrm{cA}$ \\
DKB Bi 9438 & $48,19 \mathrm{aB}$ & $42,59 \mathrm{bA}$ & $41,10 \mathrm{bA}$ \\
\hline CV (\%) & \multicolumn{4}{|}{2,78} \\
\hline
\end{tabular}

Médias seguidas de mesma letra minúscula na linha e maiúscula na coluna são iguais pelo teste de Scott-Knott a 5\% de probabilidade.

Entre as épocas de semeadura houve diferença estatística $(\mathrm{P}<0,05)$ para diâmetro da espiga de todos os híbridos semeados entre 30/11/2011 e 01/02/2012 e entre 30/11/2011 e 20/02/2012. Não ocorreu diferença estatística $(\mathrm{P}>0,05)$ para os híbridos AGN30A37H, AG8088PRO e DKB Bi 9438 para as épocas de 01/02/2012 e 20/02/2012, conforme apresentado na Tabela 2. Estas diferenças estão relacionadas à deficiência hídrica que ocorreu a partir da semeadura de 01/02/2012.

Houve interação significativa $(\mathrm{P}<0,05)$ entre híbridos e épocas de semeadura para comprimento da espiga (Tabela 3). O híbrido DKB Bi 9438 diferiu estatisticamente $(\mathrm{P}<0,05)$ dos demais $(180,94 \mathrm{~mm})$ na semeadura de 30/11/2011 (Tabela 3). Na semeadura de 01/02/2012 os híbridos Formula, P30F53H, P3646H, AG8088PRO e DKB Bi 9438 apresentaram valores estatisticamente $(\mathrm{P}<0,05)$ superiores aos demais. $\mathrm{Na}$ semeadura de 20/02/2012 os híbridos Formula, AGN30A77H, AGN30A37H, AG8088PRO e DKB Bi 9438 foram estatisticamente superiores $(\mathrm{P}<0,05) \mathrm{em}$ relação aos outros híbridos para comprimento da espiga, conforme Tabela 2.

Ocorreu diferença estatística $(\mathrm{P}<0,05)$ entre as épocas 30/11/2011 e 01/02/2012 exceto para o híbrido formula que foi estatisticamente idêntico $(\mathrm{P}>0,05)$ entre estas épocas (138,57 e 128,77 mm, respectivamente), conforme a Tabela 3. Todos os híbridos diminuíram o comprimento de espiga entre as épocas 30/11/2011 e 20/02/2012. Entre as épocas 01/02/2012 e 20/02/2012 os híbridos AGN30A77H e AGN30A37H foram estatisticamente 
iguais $(\mathrm{P}>0,05)$; os demais apresentaram diferenças entre estas épocas de semeadura. Estes dados reforçam o fato de que a menor disponibilidade de água na última época de semeadura influencia diretamente no comprimento da espiga, sendo uma das evidencias da menor produtividade na semeadura tardia.

Na Tabela 4 estão apresentados os dados da interação significativa $(\mathrm{P}<0,05)$ entre os híbridos e épocas de semeadura para o número de grãos fileira ${ }^{-1}$. Os híbridos P30F53H, P3646H e DKB Bi 9438 diferiram estatisticamente $(\mathrm{P}<0,05)$ dos demais apresentando maior quantidade de grãos fileira ${ }^{-1}$. Na semeadura seguinte $(01 / 02 / 2012)$ não ocorreu diferença $(\mathrm{P}>0,05)$ entre os híbridos estudados. Na última época de semeadura (20/02/2012) os híbridos Formula, AGN30A77H, AGN30A37H, AG8088PRO, e DKB Bi 9438 diferiram $(\mathrm{P}<0,05)$ dos demais com maior quantidade de grãos em cada fileira cujos valores foram 28,$16 ; 25,25 ; 25,75 ; 26,63$ e 24,75, respectivamente, conforme Tabela 4. Estes mesmos materiais também apresentaram maior comprimento de espiga (Tabela 3), o que conduziu à formação de maior quantidade de grãos fileira ${ }^{-1}$.

Entre as épocas de semeadura os híbridos Truck, Formula e AG8088PRO foram estatisticamente iguais $(\mathrm{P}>0,05)$ entre as duas primeiras épocas de semeadura. A semeadura em 20/02/2012 foi estatisticamente inferior $(\mathrm{P}<0,05)$ às demais para o número de grãos fileira $^{-1}$ e esta diferença é explicada pela redução da quantidade de água e temperatura no último período de semeadura. Trabalhando com cultivares diferentes, Balbinot-Júnior e Fleck (2005) observaram que o número de grãos por fileira foi o componente que apresentou a maior correlação total com a produtividade. Lima et al. (2012) observaram que a maior quantidade de grãos por fileira resultou em maior produtividade em dois híbridos estudados (2B710 e 2B707).

Tabela 3. Desdobramento da interação entre híbridos e épocas de semeadura para comprimento da espiga $(\mathrm{mm})$, na Fazenda Experimental do IF Goiano Campus Ceres, Goiás, 2011/2012

\begin{tabular}{lccc}
\hline Híbridos & \multicolumn{3}{c}{ Épocas de semeadura } \\
\cline { 2 - 4 } & $30 / 11 / 2011$ & $01 / 02 / 2012$ & $20 / 02 / 2012$ \\
\hline Truck & $142,69 \mathrm{aB}$ & $120,75 \mathrm{bB}$ & $93,40 \mathrm{cB}$ \\
Formula & $138,57 \mathrm{aB}$ & $128,70 \mathrm{aA}$ & $115,02 \mathrm{bA}$ \\
P30F53H & $160,82 \mathrm{aB}$ & $128,14 \mathrm{bA}$ & $93,14 \mathrm{cB}$ \\
P3646H & $150,32 \mathrm{aB}$ & $122,86 \mathrm{bA}$ & $84,31 \mathrm{cB}$ \\
P30F35H & $147,55 \mathrm{aB}$ & $108,79 \mathrm{bB}$ & $87,94 \mathrm{cB}$ \\
AGN30A77H & $154,69 \mathrm{aB}$ & $112,41 \mathrm{bB}$ & $116,45 \mathrm{bA}$ \\
AGN30A37H & $148,98 \mathrm{aB}$ & $111,00 \mathrm{bB}$ & $104,65 \mathrm{bA}$ \\
AG8088PRO & $153,90 \mathrm{aB}$ & $126,41 \mathrm{bA}$ & $109,44 \mathrm{cA}$ \\
DKB 390 & $143,36 \mathrm{aB}$ & $117,76 \mathrm{bB}$ & $96,76 \mathrm{cB}$ \\
DKB Bi 9438 & $180,94 \mathrm{aA}$ & $141,83 \mathrm{bA}$ & $119,52 \mathrm{cA}$ \\
\hline CV $(\%)$ & \multicolumn{4}{c}{7,43} \\
\hline
\end{tabular}

Médias seguida de mesmas letras minúsculas nas linhas e maiúsculas nas colunas são iguais pelo teste de ScottKnott a 5\% de probabilidade.
Ocorreu interação significativa $(\mathrm{P}<0,05)$ entre os híbridos e épocas de semeadura para a produtividade de grãos, conforme apresentado na Tabela 5 .

$\mathrm{Na}$ semeadura de 30/11/2011 houve diferença significativa $(\mathrm{P}<0,05)$ entre os híbridos. Os híbridos $\mathrm{P} 3646 \mathrm{H}$ e DKB Bi 9438 foram iguais estatisticamente ( $\mathrm{P}>0,05)$ com produtividade de 9.724 e $10.692 \mathrm{~kg} \mathrm{ha}^{-1}$, respectivamente e diferiram $(\mathrm{P}<0,05)$ dos demais. $\mathrm{Na}$ segunda e terceira época de semeadura não houve diferença estatística $(\mathrm{P}>0,05)$ entre os híbridos estudados, conforme a Tabela 5.

Os resultados mostram que houve uma relação entre comprimento de espiga (DKB Bi 9438, Tabela 3), número de grãos por fileira (P3646H e DKB Bi 9438, Tabela 4) e produtividade dos híbridos testados. O diâmetro da espiga não influenciou a produtividade dos híbridos, mostrando que espigas de maior diâmetro nem sempre estão relacionadas com maior produtividade.

Tabela 4. Desdobramento da interação entre híbridos e época de semeadura para número de grãos por fileira, na Fazenda Experimental do IF Goiano Campus Ceres, Goiás, 2011/2012

\begin{tabular}{lccc}
\hline Híbridos & \multicolumn{3}{c}{ Época de semeadura } \\
\hline & $30 / 11 / 2011$ & $01 / 02 / 2012$ & $20 / 02 / 2012$ \\
\hline Truck & $34,83 \mathrm{aB}$ & $31,00 \mathrm{aA}$ & $23,50 \mathrm{bB}$ \\
Formula & $35,16 \mathrm{aB}$ & $33,50 \mathrm{aA}$ & $28,16 \mathrm{bA}$ \\
P30F53H & $38,00 \mathrm{aA}$ & $32,83 \mathrm{bA}$ & $20,91 \mathrm{cB}$ \\
P3646H & $38,83 \mathrm{aA}$ & $30,58 \mathrm{bA}$ & $20,08 \mathrm{cB}$ \\
P30F35H & $36,08 \mathrm{aB}$ & $29,00 \mathrm{bA}$ & $22,58 \mathrm{cB}$ \\
AGN30A77H & $35,16 \mathrm{aB}$ & $30,16 \mathrm{bA}$ & $25,25 \mathrm{cA}$ \\
AGN30A37H & $36,50 \mathrm{aB}$ & $30,91 \mathrm{bA}$ & $25,75 \mathrm{cA}$ \\
AG8088PRO & $35,16 \mathrm{aB}$ & $32,01 \mathrm{aA}$ & $26,63 \mathrm{bA}$ \\
DKB 390 & $35,91 \mathrm{aB}$ & $27,91 \mathrm{bA}$ & $20,66 \mathrm{cB}$ \\
DKB Bi 9438 & $40,00 \mathrm{aA}$ & $31,58 \mathrm{bA}$ & $24,75 \mathrm{cA}$ \\
\hline CV (\%) & \multicolumn{4}{c}{7,60} \\
\hline
\end{tabular}

Médias seguidas de mesma letra minúsculas nas linhas e maiúsculas nas colunas são iguais pelo teste de Scott-Knott a $5 \%$ de probabilidade.

Tabela 5. Desdobramento da interação entre híbridos e épocas de semeadura para a produtividade de grãos $\left(\mathrm{kg} \mathrm{ha}^{-1}\right)$ na Fazenda Experimental do IF Goiano Campus Ceres, Goiás 2011/2012

\begin{tabular}{lccc}
\hline Híbridos & \multicolumn{3}{c}{ Época de semeadura } \\
\hline Truck & $30 / 11 / 2011$ & $01 / 02 / 2012$ & $20 / 02 / 2012$ \\
Formula & $5448 \mathrm{aB}$ & $3872 \mathrm{bA}$ & $2259,84 \mathrm{bA}$ \\
P30F53H & $8184 \mathrm{aB}$ & $4224 \mathrm{bA}$ & $2735,92 \mathrm{bA}$ \\
P3646H & $9724 \mathrm{aA}$ & $4312 \mathrm{bA}$ & $1636,80 \mathrm{cA}$ \\
P30F35H & $7656 \mathrm{aB}$ & $4796 \mathrm{bA}$ & $2219,36 \mathrm{cA}$ \\
AGN30A77H & $7304 \mathrm{aB}$ & $3080 \mathrm{bA}$ & $2170,96 \mathrm{bA}$ \\
AGN30A37H & $7260 \mathrm{aB}$ & $3916 \mathrm{bA}$ & $2377,76 \mathrm{bA}$ \\
AG8088PRO & $6512 \mathrm{aB}$ & $3388 \mathrm{bA}$ & $1239,62 \mathrm{cA}$ \\
DKB 390 & $8272 \mathrm{aB}$ & $4180 \mathrm{bA}$ & $1766,16 \mathrm{cA}$ \\
DKB Bi 9438 & $10692 \mathrm{aA}$ & $6336 \mathrm{bA}$ & $1141,54 \mathrm{cA}$ \\
\hline CV $(\%)$ & \multicolumn{4}{c}{23,61} \\
\hline
\end{tabular}

Médias seguidas de mesma letra minúsculas nas linhas e maiúsculas nas colunas são iguais pelo teste de ScottKnott a 5\% de probabilidade. 
Lima et al. (2012) verificaram que o diâmetro da espiga não influenciou na produtividade de dois híbridos estudados. Mendes et al. (2011) verificaram que o híbrido formula apresentou menor produtividade que outros três híbridos estudados, fato também observado na presente pesquisa visto que o mesmo híbrido teve desempenho menor que os demais.

Ocorreu diferença significativa $(\mathrm{P}<0,05)$ entre as épocas de semeadura para a produtividade; as maiores foram obtidas na primeira época. Na segunda e terceira época os híbridos Truck, Formula, AGN30A77H e AGN30A37H obtiveram produtividades iguais $(\mathrm{P}>0,05)$ e para os demais híbridos a produtividade foi maior na segunda época e menor na terceira de acordo com a Tabela 5 .

A semeadura realizada em novembro apresentou maior $(\mathrm{P}<0,05)$ produtividade em consequência das condições climáticas favoráveis, com maior volume de precipitações e temperaturas adequadas ocorridas durante o desenvolvimento dos híbridos. Desta forma, a adequação da época de semeadura com a menor probabilidade de ocorrência de deficiência hídrica, especialmente durante o período mais crítico de desenvolvimento da planta de milho, que ocorre da floração ao início do enchimento de grãos, pode incrementar o rendimento de grãos.

\section{Conclusões}

A semeadura da cultura do milho realizada em épocas de menor índice pluviométrico resultou na diminuição da produtividade de grãos para todos os híbridos utilizados.

Os híbridos P3646H e DKB Bi9438 apresentam maior produtividade quando semeados em novembro.

O desempenho produtivo dos híbridos é reduzido quando semeado em períodos com menor índice pluviométrico (01/02/2012, 20/02/2012).

\section{Agradecimentos}

Às empresas Irriplan (Syngenta), Herbicampo (Pioneer), Terra Viva (Morgan), Futura (Agroceres) e Uruagro (Dekalb) pela doação das sementes dos híbridos utilizados nesta pesquisa e ao IF Goiano Campus Ceres por ter disponibilizados os insumos necessários para o desenvolvimento do trabalho.

\section{Referências Bibliográficas}

ARAUJO, A. V.; BRANDÃO JUNIOR, D. S.; FERREIRA, I. C. P. V.; COSTA, C. A.; PORTO, B. B. A. Desempenho agronômico de variedades crioulas e híbridos de milho cultivados em diferentes sistemas de manejo. Revista Ciência Agronômica, Fortaleza-CE, v. 44, n. 4, p. 885-892, 2013.
ARNHOLD E. Package in the R environment for analysis of variance and complementary analyses. Brazilian Journal Veterinary Research Animal Science 50, São Paulo-SP, v. 23, n. 23, p. 488-492, 2013.

BALBINOT JÚNIOR, A. A.; FLECK, N. G. Benefício e limitações da redução do espaçamento entre linhas. Revista Plantio Direto, Sete Lagoas-MG, v. 5, n. p. 37-41, 2005.

BUSO, W. H. B.; ARNHOLD, E. Evaluation of corn hybrids under contrasting water availability conditions. Revista Caatinga, Mossoró-RN, v. 29. n. 4, p. 927-934, 2016.

CARON, B. O.; OLIVEIRA, D. M.; ELLI, E. F.; ELLOY, E.; SCHWERZ, F.; SOUZA, V. Q. de. Elementos meteorológicos sobre características morfológicas e produtivas do milho em diferentes épocas de semeadura. Científica, Jaboticabal-SP, v. 45 , n. 2, p. 105-114, 2017.

CONAB. COMPANHIA NACIONAL DE ABASTECIMENTO. Acompanhamento da safra brasileira de grãos. Brasília-DF, 2017. Disponível em: http://www.conab.gov.br/OlalaCMS/uploads/arquivos/17_03_ 14_15_28_33_boletim_graos_marco_2017bx.pdf. Acesso em: 31 mar. 2017.

CRUZ, J. C.; GARCIA, J. C.; FILHO, I. A. P.; PINTO, L. B. B.; QUEIROZ, L. R. Caracterização dos sistemas de produção de milho para altas produtividades. Sete LagoasMG: Embrapa Milho e Sorgo, 2009. 15 p. (Circular Técnica, 124).

DEMÉTRIO, C. S.; FORNASIERI FILHO, D.; CAZETTA, J. O.; CAZETTA, D. A. Desempenho de híbridos de milho submetidos a diferentes espaçamentos e densidades populacionais. Pesquisa Agropecuária Brasileira, BrasíliaDF, v. 43, n. 4, p.1691-1697, 2008.

EMYDIO, B. M., TEIXEIRA, M. C. C. Densidade de plantas e espaçamento entre linhas para o híbrido de milho BRS 1015. Pelotas-RS: Embrapa Clima Temperado, 2008. p. 1-8. (Circular Técnica, 72)

FARINELLI, R.; PENARIOL, F. G.; BORDIN, L.; COICEV, L.; FORNASIERI FILHO, D. Desempenho agronômico de cultivares de milho nos períodos de safra e safrinha. Bragantia, Campinas-SP, v. 62, n. 2, p. 235-241, 2003.

FORNASIERI FILHO, D. Manual da cultura do milho. Jaboticabal-SP: Funep - Brasil, 2007. 574 p.

FORSTHOFER, E. L. SILVA, P. R. F.; STRIEDER, M. L.; MINETTO, T.; RAMBO, L.; ARGENTA, G.; SANGOI, L.; SUHE, E.; SILVA, A. A. Desempenho agronômico e econômico do milho em diferentes níveis de manejo e épocas de semeadura. Pesquisa Agropecuária Brasileira, BrasíliaDF, v. 41, n. 3, p. 399-407, 2006.

LIMA, C. F.; ARNHOLD, E.; ARAUJO, B. L.; OLIVEIRA, G. H. F.; OLIVEIRA JUNIOR, E. A. Avaliação de híbridos de milho sob três densidades populacionais em fronteira agrícola no Maranhão. Comunicata Scientiae, Bom Jesus-PI, v. 3, n. 1, p. 30-34, 2012.

MENDES, M. C.; ROSSI, E. S.; FARIA, M. V.; ALBUQUERQUE, C. J. V.; ROSÁRIO, J. G. Efeitos de níveis de adubação nitrogenada e densidade de semeadura na cultura do milho no centro-sul do Paraná. Revista Brasileira 
de Tecnologia Aplicada nas Ciências Agrárias, Guarapuava-SP, v. 4, n. 2, p. 176-192, 2011.

PORTO, A. P. F.; VASCONCELOS, R. C.; VIANA, A. E. S.; ALMEIDA, M.R.S. Variedades de milho a diferentes espaçamentos no Planalto de Vitória da Conquista-BA. Revista Brasileira de Ciências Agrárias, Recife-PE, v. 6, n. 2, p. 208-214, 2011.

R DEVELOPMENT CORE TEAM. R: a language and environment for statistical computing [online]. Vienna, AT: R Foundation for Statistical Computing. Disponível em: http://www.R-project.org/
SILVA, P. R. F.; ARGENTA, G.; REZERA, F. Resposta de híbridos de milho Irrigado à densidade de plantas em três épocas de semeadura. Pesquisa Agropecuária Brasileira, Brasília-DF, v. 34, n. 4, p. 585-592, 1999.

SOUZA, R. S.; BASTOS, E. A.; CARDOSO, M. J.; RIBEIRO, V. Q.; BRITO, R. R. Desempenho produtivo de genótipos de milho sob déficit hídrico. Revista Brasileira de Milho e Sorgo, Sete Lagoas-MG, v. 14, n. 1, p. 49- 60, 2015. 